\title{
Perfluoroalkyl chemicals and elevated serum uric acid in US adults
}

\section{Anoop Shankar \\ Jie Xiao \\ Alan Ducatman}

Department of Community Medicine, West Virginia University School of Medicine, Morgantown, WV, USA
Correspondence: Anoop Shankar Department of Community Medicine, West Virginia University School of Medicine, I Medical Center Drive, PO Box 9190, Morgantown,

WV 26506, USA

$\mathrm{Tel}+\mathrm{I} 3042930199$

Fax +I 3042936685

Email ashankar@hsc.wvu.edu
This article was published in the following Dove Press journal:

Clinical Epidemiology

29 September 2011

Number of times this article has been viewed

Background: Perfluoroalkyl chemicals, including perfluorooctanoic acid and perfluorooctane sulfonate, are man-made chemicals that have been detected in the blood of over $98 \%$ of the US population. Serum uric acid is a novel biomarker, even mild elevations of which has been implicated in the development of hypertension, diabetes mellitus, cardiovascular disease, and chronic kidney disease. We examined the relationship of serum perfluoroalkyl chemicals, including perfluorooctanoic acid and perfluorooctane sulfonate, and elevated uric acid levels in a representative sample of US adults.

Methods: We examined 3883 participants from the 1999-2000 and 2003-2006 National Health and Nutritional Examination Surveys, a representative, multiethnic population-based survey of noninstitutionalized US adults. Serum perfluorooctanoic acid and perfluorooctane sulfonate were analyzed as quartiles. The main outcome was hyperuricemia.

Results: We found that serum levels of perfluoroalkyl chemicals, including perfluorooctanoic acid and perfluorooctane sulfonate, were positively associated with hyperuricemia. This association appeared to be independent of confounders such as age, gender, race-ethnicity, body mass index, diabetes, hypertension, and serum cholesterol. Compared with subjects in quartile 1 (referent), the multivariate odds ratio for hyperuricemia among subjects in quartile 4 was 1.97 (95\% confidence interval 1.44-2.70, $P<0.0001$ ) for perfluorooctanoic acid and $1.48 \%$ (95\% confidence interval $0.99-2.22, P=0.0433$ ) for perfluorooctane sulfonate. This observed association persisted in subgroup analysis by gender and body mass index.

Conclusion: Our results demonstrate that elevated levels of perfluoroalkyl chemicals are associated with hyperuricemia even at low perfluoroalkyl chemical exposure levels as seen in the US general population.

Keywords: perfluoroalkyl chemicals, perfluorooctanoic acid, perfluorooctane sulfonate, uric acid

\section{Introduction}

There is concern regarding human exposure to perfluoroalkyl chemicals, including perfluorooctanoic acid and perfluorooctane sulfonate, because these chemicals are persistent in the environment, bioaccumulated, biomagnified along food chains, and have been shown to cause developmental and other adverse health effects in laboratory animals. $^{1,2}$ Perfluoroalkyl chemicals have been widely used in the manufacture of industrial and consumer products such as surfactants, lubricants, polishes, paper and textile coatings, food packaging, and fire-retarding foams. ${ }^{2}$ Perfluoroalkyl chemicals have been detected in the blood of more than $98 \%$ of the US population. ${ }^{3}$ 
Uric acid is a byproduct of purine metabolism which has both oxidant as well as antioxidant properties. Several studies have shown that higher serum uric acid levels are associated with markers of inflammation, ${ }^{4}$ insulin resistance, ${ }^{5}$ and elevated lipid levels. ${ }^{6}$ Studies have also reported an association between higher serum uric acid levels and risk of developing hypertension, ${ }^{7}$ diabetes mellitus, ${ }^{8}$ chronic kidney disease, ${ }^{9}$ and cardiovascular disease. ${ }^{10}$ High levels of serum uric acid is also considered to be the underlying metabolic derailment in gout. ${ }^{11}$

Sakr et al ${ }^{12,13}$ and Costa et a ${ }^{14}$ in two separate cohorts of occupationally exposed workers reported that perfluorooctanoic acid levels are cross-sectionally associated with elevated uric acid. Recently, Steenland et a ${ }^{15}$ reported modest positive associations between both serum perfluorooctanoic acid and perfluorooctane sulfonate levels and elevated uric acid in the C8 Health Study, a community-based study of residents in six water districts in Ohio and West Virginia who were exposed to very high levels of perfluorooctanoic acid following contamination from a chemical plant. However, perfluorooctanoic acid exposure levels in the US general population are much lower than those reported in these studies which examined high-exposure populations. In this context, a recent report based on a communitybased sample of subjects exposed to perfluorooctanoic acid emissions from an industrial facility reported a concentration-dependent clearance for perfluorooctanoic acid, with half-lives of 2.9 years at higher exposure levels and 8.5 years for lower exposure levels. ${ }^{16}$ Therefore, it is also important to study perfluorooctanoic acid exposure at lower serum levels because at such concentrations these chemicals may potentially persist in the body for longer. Therefore, we examined if there was a positive association between serum perfluoroalkyl chemicals and uric acid in the National Health and Nutritional Examination Survey (NHANES), a representative, multiethnic sample of the US general population.

\section{Materials and methods}

The current study is based on six years of combined data from the 1999-2000, 2003-2004, and 2005-2006 NHANES. Detailed description of the NHANES study design and methods are available elsewhere. ${ }^{17}$ In brief, the NHANES survey included a stratified, multistage probability sample representative of the civilian noninstitutionalized US population. Selection was based on counties, blocks, households, and individuals within households, and included the oversampling of low-income persons, persons 60+ years, African Americans, and Mexican Americans in order to provide stable estimates of these groups. The survey also includes biomonitoring for different environmental chemicals, including perfluoroalkyl chemicals, in a random one third subsample of participants by the National Center for Environmental Health. Subjects were required to sign a consent form before their participation, and approval was obtained from the Human Subjects Committee at the US Department of Health and Human Service.

The current study sample consisted of 3974 participants aged $\geq 20$ years who had perfluoroalkyl chemical measurements available. We excluded subjects with missing data $(n=91)$ on uric acid and covariates included in the multivariable model, including education level, body mass index, or cholesterol levels. This resulted in 3883 participants (51.7\% women).

\section{Exposure measurements}

Age, gender, race/ethnicity, smoking status, alcohol intake ( $\mathrm{g} /$ day), level of education, history of diabetes, oral hypoglycemic intake, insulin administration, and antihypertensive medication use were assessed using a questionnaire. Individuals who had not smoked $\geq 100$ cigarettes in their lifetimes were considered never smokers; those who had smoked $\geq 100$ cigarettes in their lifetimes were considered former smokers if they answered negatively to the question "Do you smoke now?" and current smokers if they answered affirmatively. Body mass index was calculated as weight in kilograms divided by height in meters squared. Heavy drinking was defined as consumption of more than two drinks/day for the question on an average alcohol intake over the past 12 months.

Rigorous procedures with quality control checks were used in blood collection, and details about these procedures are provided in the NHANES Laboratory/ Medical Technologists Procedures Manual. ${ }^{18}$ Perfluoroalkyl chemicals were measured in serum by the National Center for Environmental Health using automated solid-phase extraction coupled to isotope dilution high-performance liquid chromatography-tandem mass spectrometry; details of laboratory methods are available elsewhere. ${ }^{3}$ Our study examined the perfluoroalkyl chemicals, perfluorooctanoic acid and perfluorooctane sulfonate, that were detected in greater than $98 \%$ of people. Values below the limit of detection were reported by NHANES as the limit of detection divided by the square root of 2 . 
Serum total cholesterol was measured enzymatically. Seated systolic and diastolic blood pressures were measured using a mercury sphygmomanometer according to the American Heart Association and Seventh Joint National Committee (JNC7) recommendations. ${ }^{19} \mathrm{Up}$ to three measurements were averaged for systolic and diastolic pressures. Patients were considered hypertensive if they reported current blood pressure-reducing medication use and/or had systolic blood pressures $\geq 140 \mathrm{mmHg}$ and/or diastolic blood pressures $\geq 90 \mathrm{mmHg}$.

\section{Outcome of interest}

The main outcome of interest was serum uric acid level or the presence of hyperuricemia. Uric acid was measured using the Beckman Synchron LX20 system. Details of laboratory measurement are available online..$^{20}$ In brief, uric acid is oxidized by uricase to produce allatoin and hydrogen peroxide. The hydrogen peroxide reacts with 4-aminoantipyrine and 3,5-dichloro-2-hydroxybenzene sulfonate in a reaction catalyzed by peroxidase to produce a colored product. The Beckman Synchron LX20 system monitors the change in absorbance at $520 \mathrm{~nm}$ at a fixed time interval. The change in absorbance is directly proportional to the concentration of uric acid in the sample. Coulston Foundation at Alamogordo, New Mexico, performed testing in 1999-2000 and Collaborative Laboratory Services at Ottumwa, Iowa, performed testing in 2003-2004. Hyperuricemia was defined as serum uric acid levels $>6.8 \mathrm{mg} / \mathrm{dL}$ in men and $>6.0 \mathrm{mg} / \mathrm{dL}$ in women. ${ }^{11}$

\section{Statistical analysis}

Serum perfluoroalkyl chemicals, including perfluorooctanoic acid and perfluorooctane sulfonate, were analyzed both as a continuous as well as a categorical variable. For analysis as a continuous variable, perfluoroalkyl chemical values were logtransformed (base 2) as a result of their skewed distribution. We also categorized serum perfluoroalkyl chemicals into quartiles. We ran linear regression models with serum perfluoroalkyl chemical quartiles as the independent variable to examine the mean change in serum uric acid with increasing categories of perfluoroalkyl chemical, taking the lowest perfluoroalkyl chemical quartile as the referent. We ran three nested models, ie, the unadjusted model, the age and gender-adjusted model, and the multivariable-adjusted model, additionally adjusting for race-ethnicity (non-Hispanic whites, non-Hispanic blacks, Mexican Americans, others), education categories ( $<$ high school, high school, $>$ high school), smoking (never, former, current), alcohol intake (heavy drinker), body mass index $\left(\mathrm{kg} / \mathrm{m}^{2}\right)$, hypertension (absent, present), diabetes (absent, present), and serum total cholesterol (mg/dL). Subsequently, we ran multivariable logistic regression models to calculate the odds ratio ([OR], 95\% confidence interval $[\mathrm{CI}]$ ) of hyperuricemia for each higher perfluoroalkyl chemical level by taking the lowest category as the referent. Trends in the OR of hyperuricemia across increasing serum perfluoroalkyl chemical levels were determined by modeling perfluoroalkyl chemical categories as an ordinal variable. As recommended by the National Center for Health Statistics, ${ }^{21}$ sample weights that account for the unequal probabilities of selection, oversampling, and nonresponse in the NHANES survey were applied for all analyses. Analyses were conducted using SUDAAN (version 8.0, Research Triangle Institute, Research Triangle Park, NC) and SAS (version 9.2, SAS Institute, Cary, NC) software. Standard errors were estimated using the Taylor series linearization method.

\section{Results}

Table 1 presents the characteristics of the population. Overall, this was a middle-aged representative sample of the US population. It comprised $51.7 \%$ women,

Table I Characteristics of study population

\begin{tabular}{ll}
\hline Characteristics & Percentages or mean values \pm SE \\
\hline Unweighted sample size & 3883 \\
Age, years & $46.4 \pm 0.5$ \\
Women, \% & 51.7 \\
Race-ethnicity, \% & 73.5 \\
Non-Hispanic whites & 10.7 \\
Non-Hispanic blacks & 7.8 \\
Mexican Americans & 8.0 \\
Others & \\
Education categories, \% & 18.5 \\
Below high school & 27.1 \\
High school & 54.4 \\
Above high school & \\
Smoking, \% & 49.9 \\
Never smoker & 26.0 \\
Former smoker & 24.1 \\
Current smoker & \\
Alcohol intake, \% & 24.3 \\
Heavy drinker & $28.5 \pm 0.2$ \\
Body mass index, kg/m & $200.7 \pm 0.9$ \\
Total cholesterol, $\mathrm{mg} / \mathrm{dL}$ & 10.2 \\
Diabetes mellitus, \% & 31.2 \\
Hypertension, \% & $5.4 \pm 0.04$ \\
Serum uric acid, mg/dL & 19.2 \\
Hyperuricemia, \% &
\end{tabular}

Abbreviation: SE, standard error of the mean. 
Table 2 Association between serum PFOA level and uric acid levels

\begin{tabular}{|c|c|c|c|c|}
\hline Plasma PFC level* & Sample size & $\begin{array}{l}\text { Unadjusted mean } \\
\text { change in uric acid, } \\
\mathrm{mg} / \mathrm{dL}(95 \% \mathrm{Cl})\end{array}$ & $\begin{array}{l}\text { Age, gender-adjusted } \\
\text { mean change in uric acid, } \\
\mathrm{mg} / \mathrm{dL}(95 \% \mathrm{Cl})\end{array}$ & $\begin{array}{l}\text { Multivariate-adjusted } \\
\text { mean change in uric } \\
\text { acid, } \mathrm{mg} / \mathrm{dL}(95 \% \mathrm{Cl})^{\ddagger}\end{array}$ \\
\hline \multicolumn{5}{|l|}{ PFOA* } \\
\hline Quartile I & 984 & I (referent) & I (referent) & I (referent) \\
\hline Quartile 2 & 931 & $0.20(0.05,0.34)$ & $0.15(0.03,0.27)$ & $0.14(0.04,0.25)$ \\
\hline Quartile 3 & 1003 & $0.40(0.23,0.56)$ & $0.37(0.23,0.5 \mathrm{I})$ & $0.37(0.25,0.49)$ \\
\hline Quartile 4 & 965 & $0.56(0.43,0.68)$ & $0.48(0.35,0.60)$ & $0.44(0.32,0.56)$ \\
\hline$P$ trend & & $<0.000$ I & $<0.0001$ & $<0.0001$ \\
\hline Log-transformed PFOA & & $0.45(0.37,0.53)$ & $0.25(0.17,0.32)$ & $0.22(0.15,0.30)$ \\
\hline \multicolumn{5}{|l|}{$\mathrm{PFOS}^{\dagger}$} \\
\hline Quartile I & 967 & I (referent) & I (referent) & I (referent) \\
\hline Quartile 2 & 969 & $0.12(-0.07,0.30)$ & $0.16(-0.01,0.32)$ & $0.18(0.05,0.31)$ \\
\hline Quartile 3 & 978 & $0.28(0.10,0.45)$ & $0.24(0.05,0.43)$ & $0.22(0.04,0.40)$ \\
\hline Quartile 4 & 969 & $0.29(0.11,0.46)$ & $0.26(0.09,0.44)$ & $0.27(0.13,0.41)$ \\
\hline$P$ trend & & 0.0006 & 0.0051 & 0.0018 \\
\hline Log-transformed PFOS & & $0.40(0.3 \mathrm{I}, 0.50)$ & $0.16(0.05,0.26)$ & $0.14(0.05,0.23)$ \\
\hline
\end{tabular}

Notes: *Plasma PFOA quartiles: quartile I ( $<2.4 \mathrm{ppb})$, quartile 2 (2.4-3.4 ppb), quartile 3 (3.5-5.I ppb), quartile 4 ( $>5.1 \mathrm{ppb})$; in men: quartile I (<3.2 ppb), quartile 2 (3.2-4.5 ppb), quartile 3 (4.6-6.4 ppb), quartile 4 (>6.4 ppb); ${ }^{\dagger}$ plasma PFOS quartiles: quartile I (<II.2 ppb), quartile 2 (II .2-I7.8 ppb), quartile 3 (I7.9-27.9 Ppb), quartile 4 ( $>27.9 \mathrm{ppb})$; in men: quartile I (<I7.5 ppb), quartile 2 (I7.5-24.7 ppb), quartile 3 (24.8-35.6 ppb), quartile 4 ( $>35.6 \mathrm{ppb})$; $\neq$ adjusted for age (years), gender (men, women), race-ethnicity (non-Hispanic whites, non-Hispanic blacks, Mexican Americans, others), education categories (<high school, high school, $>$ high school), smoking (never, former, current), alcohol intake (heavy drinker), body mass index $\left(\mathrm{kg} / \mathrm{m}^{2}\right)$, hypertension (absent, present), diabetes (absent, present), and serum total cholesterol ( $\mathrm{mg} / \mathrm{dL}$ ). Abbreviations: $\mathrm{Cl}$, confidence interval; PFOA, perfluorooctanoic acid; PFOS, perfluorooctane sulfonate.

73.5\% non-Hispanic whites, $10.7 \%$ non-Hispanic blacks, and 7.8\% Mexican Americans. The mean serum uric acid level was $5.4 \mathrm{mg} / \mathrm{dL}$, and $19.2 \%$ of the population had hyperuricemia.

Table 2 presents the association between increasing serum perfluorooctanoic acid, perfluorooctane sulfonate, and uric acid in the whole study sample. We observed a positive association between increasing quartiles of serum perfluorooctanoic acid and perfluorooctane sulfonate and a change in uric acid levels in the unadjusted, age-adjusted, and gender-adjusted models, as well as the multivariableadjusted models. Models evaluating trend in this association were also statistically significant.

Tables 3 and 4 present the association between increasing serum perfluorooctanoic acid and perfluorooctane sulfonate and serum uric acid stratified by gender and body mass index categories, respectively. Similar to the results in Table 2, we observed a positive association between increasing quartiles of serum perfluorooctanoic acid and perfluorooctane sulfonate and change in uric acid levels. Models evaluating trend in this association were also statistically significant.

Table 5 presents the association between increasing serum perfluorooctanoic acid and perfluorooctane sulfonate and the presence of hyperuricemia. We observed a positive association between increasing quartiles of serum perfluorooctanoic acid and perfluorooctane sulfonate and the odds of hyperuricemia in the unadjusted, age-adjusted, and gender-adjusted models, as well as the multivariable-adjusted models. Models evaluating trend in this association were also statistically significant.

\section{Discussion}

In a representative sample of US adults, we found that serum perfluoroalkyl chemical levels were positively associated with elevated uric acid. The association was found to be independent of age, gender, race-ethnicity, education, smoking, alcohol intake, body mass index, hypertension, diabetes, and serum total cholesterol. We found that both perfluorooctanoic acid and perfluorooctane sulfonate levels were associated with elevated uric acid in separate analyses. Our results contribute to the existing literature, which had demonstrated an association between perfluoroalkyl chemicals and uric acid in groups who were exposed to very high perfluoroalkyl chemical levels, by suggesting that perfluoroalkyl chemical levels are positively related to uric acid, even at low exposure levels as seen in the US general population.

Hyperuricemia is the underlying mechanism in gout, a clinical condition where high levels of serum uric acid result in deposition of monosodium urate crystals in the synovial fluid of joints and in the interstitial space and tubules of renal cells resulting, respectively, in arthritis and kidney disease. ${ }^{11}$ Furthermore, emerging animal and human studies suggest 
Table 3 Association between plasma PFOA level and uric acid levels by gender

\begin{tabular}{|c|c|c|c|c|c|c|}
\hline \multirow[t]{2}{*}{ Quartile } & \multicolumn{3}{|l|}{ Men } & \multicolumn{3}{|l|}{ Women } \\
\hline & $\begin{array}{l}\text { Sample } \\
\text { size }\end{array}$ & $\begin{array}{l}\text { Unadjusted mean } \\
\text { change in uric acid, } \\
\mathrm{mg} / \mathrm{dL}(95 \% \mathrm{Cl})\end{array}$ & $\begin{array}{l}\text { Multivariate-adjusted } \\
\text { mean change in uric } \\
\text { acid, } \mathrm{mg} / \mathrm{dL}(95 \% \mathrm{Cl})^{\ddagger}\end{array}$ & $\begin{array}{l}\text { Sample } \\
\text { size }\end{array}$ & $\begin{array}{l}\text { Unadjusted mean } \\
\text { change in uric acid, } \\
\mathrm{mg} / \mathrm{dL}(95 \% \mathrm{Cl})\end{array}$ & $\begin{array}{l}\text { Multivariate- } \\
\text { adjusted mean } \\
\text { change in uric acid, } \\
\mathrm{mg} / \mathrm{dL}(95 \% \mathrm{Cl})^{\ddagger}\end{array}$ \\
\hline \multicolumn{7}{|l|}{ PFOA* } \\
\hline Quartile I & 463 & I (referent) & I (referent) & 521 & I (referent) & I (referent) \\
\hline Quartile 2 & 455 & $0.14(-0.03,0.30)$ & $0.08(-0.06,0.22)$ & 476 & $0.16(0.01,0.3 \mathrm{I})$ & $0.14(-0.03,0.30)$ \\
\hline Quartile 3 & 471 & $0.39(0.18,0.61)$ & $0.33(0.15,0.5 \mathrm{I})$ & 532 & $0.37(0.20,0.54)$ & $0.29(0.15,0.43)$ \\
\hline Quartile 4 & 468 & $0.48(0.32,0.64)$ & $0.4 \mathrm{I}(0.24,0.57)$ & 497 & $0.50(0.32,0.69)$ & $0.33(0.12,0.54)$ \\
\hline$P$ trend & & $<0.0001$ & $<0.0001$ & & $<0.0001$ & 0.0012 \\
\hline Log-transformed PFOA & 1857 & $0.25(0.13,0.37)$ & $0.21(0.09,0.34)$ & 2026 & $0.27(0.18,0.35)$ & $0.16(0.06,0.26)$ \\
\hline \multicolumn{7}{|l|}{ PFOS $^{\dagger}$} \\
\hline Quartile I & 466 & I (referent) & I (referent) & 501 & I (referent) & I (referent) \\
\hline Quartile 2 & 460 & $0.28(0.06,0.50)$ & $0.20(-0.02,0.43)$ & 509 & $0.07(-0.15,0.29)$ & $0.13(-0.05,0.32)$ \\
\hline Quartile 3 & 470 & $0.26(0.04,0.48)$ & $0.20(-0.0 \mathrm{I}, 0.4 \mathrm{I})$ & 508 & $0.32(0.10,0.55)$ & $0.19(-0.04,0.4 I)$ \\
\hline Quartile 4 & 461 & $0.28(0.06,0.49)$ & $0.23(0.02,0.44)$ & 508 & $0.42(0.16,0.69)$ & $0.23(-0.02,0.48)$ \\
\hline$P$ trend & & 0.0223 & 0.0499 & & 0.0006 & 0.0706 \\
\hline Log-trasnformed PFOS & & $0.16(0.06,0.26)$ & $0.11(0.00,0.22)$ & & $0.24(0.09,0.39)$ & $0.13(-0.01,0.27)$ \\
\hline
\end{tabular}

Notes: *Plasma PFOA quartiles: quartile I ( $<2.4 \mathrm{ppb})$, quartile 2 (2.4-3.4 ppb), quartile 3 (3.5-5.I ppb), quartile 4 ( $>5.1 \mathrm{ppb})$; in men: quartile I (<3.2 ppb), quartile 2 (3.2-4.5 ppb), quartile 3 (4.6-6.4 ppb), quartile 4 (>6.4 ppb); ${ }^{\dagger}$ plasma PFOS quartiles: quartile I (<II.2 ppb), quartile 2 (II.2-I7.8 ppb), quartile 3 (I7.9-27.9 ppb), quartile 4 ( $>27.9 \mathrm{ppb})$; in men: quartile I (<I7.5 ppb), quartile 2 (I7.5-24.7 ppb), quartile 3 (24.8-35.6 ppb), quartile 4 ( $>35.6$ ppb); ${ }^{\ddagger}$ adjusted for age (years), gender (men, women), race-ethnicity (non-Hispanic whites, non-Hispanic blacks, Mexican Americans, others), education categories (<high school, high school, $>$ high school), smoking (never, former, current), alcohol intake (heavy drinker), body mass index $\left(\mathrm{kg} / \mathrm{m}^{2}\right)$, hypertension (absent, present), diabetes (absent, present), and serum total cholesterol ( $\left.\mathrm{mg} / \mathrm{dL}\right)$. Abbreviations: $\mathrm{Cl}$, confidence interval; PFOA, perfluorooctanoic acid; PFOS, perfluorooctane sulfonate.

that even mild elevations in serum uric acid may be associated with increased risk of developing hypertension, chronic kidney disease, and cardiovascular outcomes. ${ }^{22}$ Therefore, identifying environmental factors associated with elevated levels of serum uric acid may have clinical and public health significance.

There is limited previous research available on the effect of perfluoroalkyl chemicals on uric acid, with only two occupational studies and one community-based study examining this hypothesis. In a cross-sectional study of 1025 active workers exposed to perfluorooctanoic acid from a chemical plant based in the US, Sakr et al ${ }^{12,13}$ reported a modest positive association between serum perfluorooctanoic acid levels and uric acid. In a more recent study of 53 male workers at a perfluorooctanoic acid production plant from Italy, Costa et $\mathrm{al}^{14}$ reported a similar positive association between serum perfluorooctanoic acid levels and uric acid. In a large, community-based, cross-sectional study of perfluorooctanoic acid and perfluorooctane sulfonate and uric acid among 54,951 adult community residents in Ohio and West Virginia, who lived or worked in six water districts contaminated with perfluorooctanoic acid from a chemical plant, Steenland et $\mathrm{al}^{15}$ reported that the risk of hyperuricemia risk increased modestly with increasing perfluorooctanoic acid; the OR by quintile of perfluorooctanoic acid reported in that study were 1.00, 1.33
(95\% CI, 1.24-1.43), 1.35 (95\% CI, 1.26-1.45), $1.47(95 \%$ CI, 1.37-1.58), and 1.47 (95\% CI, 1.37-1.58; test for trend, $P<0.0001)$. However, all of these studies were based on samples of individuals exposed to perfluorooctanoic acid levels that are much higher than the background exposure levels in the US general population.

Exposure levels of perfluoroalkyl chemicals are important, because a recent study showed that the half-life of perfluorooctanoic acid was 2.9 years at higher exposure levels and 8.5 years at lower exposure levels, suggesting a concentration-dependent clearance of these chemicals from the human body. ${ }^{16}$ These half-life values are higher than those reported in previous studies examining occupational workers. ${ }^{23,24}$ Therefore, there is a need to examine the putative association between serum perfluoroalkyl chemical levels and uric acid at these lower levels also. It is in this context that the results of our study employing the nationally representative NHANES survey are relevant. We found that both serum perfluorooctanoic acid and perfluorooctane sulfonate levels are positively associated with uric acid at low exposure levels seen in the US general population, even after adjusting for a variety of confounders.

The biological mechanisms underlying this observed positive association between serum uric acid and perfluoroalkyl chemical levels are not clear. Recent studies have reported that perfluorooctanoic acid exposure may be 
Table 4 Association between plasma PFOA level and uric acid levels according to body mass index categories

\begin{tabular}{|c|c|c|c|c|c|c|}
\hline \multirow[t]{2}{*}{ Quartile } & \multicolumn{3}{|c|}{ BMI $<30 \mathrm{~kg} / \mathrm{m}^{2}$} & \multicolumn{3}{|c|}{ BMI $\geq 30 \mathrm{~kg} / \mathrm{m}^{2}$} \\
\hline & $\begin{array}{l}\text { Sample } \\
\text { size }\end{array}$ & $\begin{array}{l}\text { Unadjusted mean } \\
\text { change in uric acid, } \\
\mathrm{mg} / \mathrm{dL}(95 \% \mathrm{Cl})\end{array}$ & $\begin{array}{l}\text { Multivariate- } \\
\text { adjusted mean } \\
\text { change in uric acid, } \\
\mathrm{mg} / \mathrm{dL}(95 \% \mathrm{Cl})^{\ddagger}\end{array}$ & $\begin{array}{l}\text { Sample } \\
\text { size }\end{array}$ & $\begin{array}{l}\text { Unadjusted mean } \\
\text { change in uric acid, } \\
\mathrm{mg} / \mathrm{dL}(95 \% \mathrm{Cl})\end{array}$ & $\begin{array}{l}\text { Multivariate- } \\
\text { adjusted mean } \\
\text { change in uric acid, } \\
\mathrm{mg} / \mathrm{dL}(95 \% \mathrm{Cl})^{\ddagger}\end{array}$ \\
\hline \multicolumn{7}{|l|}{ PFOA* } \\
\hline Quartile I & 653 & I (referent) & I (referent) & 331 & I (referent) & I (referent) \\
\hline Quartile 2 & 597 & $0.17(0.01,0.33)$ & $0.16(0.04,0.27)$ & 334 & $0.24(-0.02,0.49)$ & $0.11(-0.11,0.32)$ \\
\hline Quartile 3 & 665 & $0.37(0.19,0.54)$ & $0.33(0.20,0.46)$ & 338 & $0.52(0.25,0.79)$ & $0.46(0.22,0.70)$ \\
\hline Quartile 4 & 635 & $0.52(0.35,0.68)$ & $0.40(0.26,0.55)$ & 330 & $0.65(0.34,0.96)$ & $0.49(0.25,0.73)$ \\
\hline$P$ trend & & $<0.0001$ & $<0.0001$ & & $<0.0001$ & $<0.0001$ \\
\hline Log-transformed PFOA & 2550 & $0.45(0.36,0.55)$ & $0.21(0.13,0.30)$ & 1333 & $0.46(0.26,0.66)$ & $0.23(0.05,0.4 I)$ \\
\hline \multicolumn{7}{|l|}{$\mathrm{PFOS}^{\dagger}$} \\
\hline Quartile I & 624 & I (referent) & I (referent) & 343 & I (referent) & I (referent) \\
\hline Quartile 2 & 653 & $0.12(-0.10,0.34)$ & $0.22(0.06,0.38)$ & 316 & $0.22(-0.01,0.44)$ & $0.11(-0.08,0.30)$ \\
\hline Quartile 3 & 652 & $0.22(0.06,0.38)$ & $0.16(-0.02,0.34)$ & 326 & $0.40(0.05,0.75)$ & $0.34(0.01,0.67)$ \\
\hline Quartile 4 & 621 & $0.31(0.12,0.50)$ & $0.34(0.18,0.50)$ & 348 & $0.28(-0.06,0.61)$ & $0.13(-0.18,0.44)$ \\
\hline$P$ trend & & 0.0015 & 0.0005 & & 0.0600 & 0.2348 \\
\hline Log-transformed PFOS & & $0.42(0.35,0.48)$ & $0.16(0.08,0.24)$ & & $0.39(0.18,0.59)$ & $0.10(-0.11,0.30)$ \\
\hline
\end{tabular}

Notes: *Plasma PFOA quartiles: quartile I ( $<2.4 \mathrm{ppb})$, quartile $2(2.4-3.4 \mathrm{ppb})$, quartile $3(3.5-5.1 \mathrm{ppb})$, quartile 4 ( $>5.1 \mathrm{ppb})$; in men: quartile I ( $<3.2 \mathrm{ppb})$, quartile 2 (3.2-4.5 ppb), quartile $3(4.6-6.4 \mathrm{ppb})$, quartile 4 ( $>6.4 \mathrm{ppb})$; ${ }^{\dagger}$ plasma PFOS quartiles: quartile I (<II.2 ppb), quartile 2 (II.2-17.8 ppb), quartile 3 (I7.9-27.9 ppb), quartile 4 ( $>27.9 \mathrm{ppb})$; in men: quartile I (<17.5 ppb), quartile 2 (17.5-24.7 ppb), quartile 3 (24.8-35.6 ppb), quartile 4 ( $>35.6 \mathrm{ppb})$; ${ }^{\ddagger}$ adjusted for age (years), gender (men, women), race-ethnicity (non-Hispanic whites, non-Hispanic blacks, Mexican Americans, others), education categories ( $<$ high school, high school, $>$ high school), smoking (never, former, current), alcohol intake (heavy drinker), body mass index $\left(\mathrm{kg} / \mathrm{m}^{2}\right)$, hypertension (absent, present), diabetes (absent, present), and serum total cholesterol (mg/dL). Abbreviations: BMI, body mass index; $\mathrm{Cl}$, confidence interval; PFOA, perfluorooctanoic acid; PFOS, perfluorooctane sulfonate.

related to oxidative stress in liver ${ }^{25,26}$ and endothelial cells. Similarly, elevations in serum uric acid may be an indirect measure of oxidative stress. ${ }^{27}$ Another possibility is that organic anion transporters 1 and 3, which are involved in the tubular secretion of uric acid, ${ }^{28}$ have been reported to have a high affinity for perfluorooctanoic acid. ${ }^{29}$ Therefore, it is possible that perfluorooctanoic acid may compete with the excretion of uric acid.

The main strengths of our study include its populationbased nature, inclusion of a representative multiethnic sample,

Table 5 Association between plasma PFOA level and hyperuricemia

\begin{tabular}{|c|c|c|c|c|}
\hline Plasma PFC level* & $\begin{array}{l}\text { Number at risk } \\
\text { (hyperuricemia } \\
\text { weighted \%) }\end{array}$ & $\begin{array}{l}\text { Unadjusted OR } \\
(95 \% \mathrm{Cl})\end{array}$ & $\begin{array}{l}\text { Age, gender-adjusted OR } \\
(95 \% \mathrm{Cl})\end{array}$ & $\begin{array}{l}\text { Multivariate-adjusted OR } \\
(95 \% \mathrm{Cl})^{\ddagger}\end{array}$ \\
\hline \multicolumn{5}{|l|}{ PFOA* } \\
\hline Quartile I & $984(13.6)$ & I (referent) & I (referent) & I (referent) \\
\hline Quartile 2 & 931 (15.7) & $1.18(0.82,1.69)$ & I. $17(0.8 \mathrm{I}, \mathrm{I} .69)$ & I. $14(0.78,1.67)$ \\
\hline Quartile 3 & $1003(22.0)$ & $\mathrm{I} .79(\mathrm{I} .27,2.5 \mathrm{I})$ & $1.84(1.33,2.55)$ & $1.90(1.35,2.69)$ \\
\hline Quartile 4 & $965(23.7)$ & $1.97(1.50,2.59)$ & $1.97(1.48,2.62)$ & $1.97(1.44,2.70)$ \\
\hline$P$ trend & & $<0.0001$ & $<0.0001$ & $<0.0001$ \\
\hline Log-transformed PFOA & & $1.62(1.35,1.93)$ & $1.42(1.19,1.7 \mathrm{I})$ & $1.43(1.16,1.76)$ \\
\hline \multicolumn{5}{|l|}{ PFOS ${ }^{\dagger}$} \\
\hline Quartile I & $967(14.8)$ & I (referent) & I (referent) & I (referent) \\
\hline Quartile 2 & $969(18.9)$ & $1.34(1.00,1.81)$ & $1.38(1.02,1.87)$ & $1.46(1.11,1.91)$ \\
\hline Quartile 3 & $978(22.6)$ & $1.68(1.20,2.34)$ & $1.63(1.15,2.32)$ & $1.69(1.19,2.40)$ \\
\hline Quartile 4 & $969(20.8)$ & 1.51 (I.0I, 2.24) & $1.42(0.94,2.16)$ & $1.48(0.99,2.22)$ \\
\hline$P$ trend & & 0.0180 & 0.0611 & 0.0433 \\
\hline Log-transformed PFOS & & I.47 (I.20, I.79) & $1.21(0.98,1.50)$ & $\mathrm{I} .2 \mathrm{I}(0.97, \mathrm{I} .5 \mathrm{I})$ \\
\hline
\end{tabular}

Notes: *Plasma PFOA quartiles: quartile I ( $<2.4 \mathrm{ppb})$, quartile 2 (2.4-3.4 ppb), quartile 3 (3.5-5.I ppb), quartile 4 ( $>5.1 \mathrm{ppb})$; in men: quartile I $(<3.2 \mathrm{ppb})$, quartile 2 (3.2-4.5 ppb), quartile $3(4.6-6.4 \mathrm{ppb})$, quartile 4 (>6.4 ppb); ${ }^{\dagger}$ plasma PFOS quartiles: quartile I (<II.2 ppb), quartile 2 (II.2-I7.8 ppb), quartile 3 (I7.9-27.9 ppb), quartile 4 ( $>27.9 \mathrm{ppb})$; in men: quartile I (<17.5 ppb), quartile 2 ( $17.5-24.7 \mathrm{ppb})$, quartile 3 (24.8-35.6 ppb), quartile 4 ( $>35.6 \mathrm{ppb})$; ${ }^{\neq}$adjusted for age (years), gender (men, women), race-ethnicity (non-Hispanic whites, non-Hispanic blacks, Mexican Americans, others), education categories (<high school, high school, $>$ high school), smoking (never, former, current), alcohol intake (heavy drinker), body mass index $\left(\mathrm{kg} / \mathrm{m}^{2}\right)$, hypertension (absent, present), diabetes (absent, present), and serum total cholesterol ( $\mathrm{mg} / \mathrm{dL}$ ). Abbreviations: $\mathrm{Cl}$, confidence interval; OR, odds ratio; PFOA, perfluorooctanoic acid; PFOS, perfluorooctane sulfonate; PFC, perfluoroalkyl chemicals. 
adequate sample size, objective measurement of diabetes status following current guidelines, and the availability of extensive data on confounders for multivariate adjustment. The main limitation of our study is the cross-sectional nature of NHANES. Therefore, similar to previous studies that examined the association between other environmental exposures and disease states using the NHANES data, the temporal nature of the association between perfluoroalkyl chemicals and diabetes cannot be concluded from the current study. Another limitation is that adjustment for variables that are potential mediators, such as hypertension in the multivariate model, may be an overadjustment, and therefore may have led to an underestimation of the true association between serum perfluoroalkyl chemical levels and uric acid. It is possible that the true association may be in fact of stronger magnitude.

In summary, we found that serum perfluoroalkyl chemical levels were positively associated with elevated uric acid in a representative, multiethnic sample of US adults. This association was found to be independent of age, gender, race-ethnicity, education, smoking, alcohol intake, body mass index, hypertension, diabetes, and serum total cholesterol. Our results contribute to the literature by suggesting that perfluoroalkyl chemical levels are related to uric acid, even at low exposure levels, in the general population.

\section{Acknowledgments}

This study was funded by an American Heart Association National Clinical Research Program award and a National Institutes of Health/National Institute of Environmental Health Sciences grant (NIH/NIEHS 5R03ES018888-02).

\section{Disclosure}

The authors report no conflicts of interest in this work.

\section{References}

1. Lau C, Anitole K, Hodes C, Lai D, Pfahles-Hutchens A, Seed J. Perfluoroalkyl acids: a review of monitoring and toxicological findings. Toxicol Sci. 2007;99:366-394.

2. Steenland K, Fletcher T, Savitz DA. Epidemiologic evidence on the health effects of perfluorooctanoic acid (PFOA). Environ Health Perspect. 2010;118:1100-1108.

3. Calafat AM, Wong LY, Kuklenyik Z, Reidy JA, Needham LL. Polyfluoroalkyl chemicals in the US population: data from the National Health and Nutrition Examination Survey (NHANES) 2003-2004 and comparisons with NHANES 1999-2000. Environ Health Perspect. 2007; 115:1596-1602.

4. Kang DH, Park SK, Lee IK, Johnson RJ. Uric acid-induced C-reactive protein expression: implication on cell proliferation and nitric oxide production of human vascular cells. J Am Soc Nephrol. 2005;16: $3553-3562$.
5. Facchini F, Chen YD, Hollenbeck CB, Reaven GM. Relationship between resistance to insulin-mediated glucose uptake, urinary uric acid clearance, and plasma uric acid concentration. JAMA. 1991;266: 3008-3011.

6. Lin SD, Tsai DH, Hsu SR. Association between serum uric acid level and components of the metabolic syndrome. J Chin Med Assoc. 2006; 69:512-516.

7. Shankar A, Klein R, Klein BE, Nieto FJ. The association between serum uric acid level and long-term incidence of hypertension: Populationbased cohort study. J Hum Hypertens. 2006;20:937-945.

8. Bhole V, Choi JW, Kim SW, de VM, Choi H. Serum uric acid levels and the risk of type 2 diabetes: a prospective study. Am J Med. 2010; 123:957-961.

9. Cain L, Shankar A, Ducatman AM, Steenland K. The relationship between serum uric acid and chronic kidney disease among Appalachian adults. Nephrol Dial Transplant. 2010;25:3593-3599.

10. Sinan DO, Kabakci G, Okutucu S, et al. The association between serum uric acid level and coronary artery disease. Int J Clin Pract. 2010;64: 900-907.

11. Terkeltaub RA. Clinical practice. Gout. N Engl J Med. 2003;349: 1647-1655.

12. Sakr CJ, Kreckmann KH, Green JW, Gillies PJ, Reynolds JL, Leonard RC. Cross-sectional study of lipids and liver enzymes related to a serum biomarker of exposure (ammonium perfluorooctanoate or APFO) as part of a general health survey in a cohort of occupationally exposed workers. J Occup Environ Med. 2007;49:1086-1096.

13. Sakr CJ, Leonard RC, Kreckmann KH, Slade MD, Cullen MR. Longitudinal study of serum lipids and liver enzymes in workers with occupational exposure to ammonium perfluorooctanoate. $J$ Occup Environ Med. 2007;49:872-879.

14. Costa G, Sartori S, Consonni D. Thirty years of medical surveillance in perfluooctanoic acid production workers. $J$ Occup Environ Med. 2009;51:364-372.

15. Steenland K, Tinker S, Shankar A, Ducatman A. Association of perfluorooctanoic acid (PFOA) and perfluorooctane sulfonate (PFOS) with uric acid among adults with elevated community exposure to PFOA. Environ Health Perspect. 2010;118:229-233.

16. Seals R, Bartell SM, Steenland K. Accumulation and clearance of PFOA in current and former residents of an exposed community. Environ Health Perspect. 2011;119:119-124.

17. National Center for Health Statistics-CDC. National Health and Nutrition Examination Survey 2003-2004: reference manuals and reports. Available at: http://www cdc gov/nchs/nhanes/nhanes2003-2004/ nhanes03_04 htm. Accessed Ocober 22, 2010.

18. National Center for Health Statistics-CDC. Procedures for Laboratory Components of NHANES. Available at: http://www cde gov/nchs/data/ nhanes/nhanes_03_04/blood03_04 pdf. Accessed Ocober 22, 2010.

19. Chobanian AV, Bakris GL, Black HR, et al. Seventh report of the Joint National Committee on Prevention, Detection, Evaluation, and Treatment of High Blood Pressure. Hypertension. 2003;42: $1206-1252$.

20. National Center for Health Statistics-CDC. Laboratory procedure manual for uric acid. Available at: http://www cdc gov/nchs/data/ nhanes/nhanes_03_04/140_c_met_uric_acid pdf. Accessed Ocober 22, 2010.

21. National Center for Health Statistics-CDC. Analytical and reporting guidelines for NHANES. Available at: http://www cdc gov/nchs/data/ nhanes/nhanes_03_04/nhanes_analytic_guidelines_dec_2005pdf. Accessed Ocober 22, 2010.

22. Feig DI, Kang DH, Johnson RJ. Uric acid and cardiovascular risk. N Engl J Med. 2008;359:1811-1821.

23. Olsen GW, Chang SC, Noker PE, et al. A comparison of the pharmacokinetics of perfluorobutanesulfonate (PFBS) in rats, monkeys, and humans. Toxicology. 2009;256:65-74.

24. Karrman A, Domingo JL, Llebaria X, et al. Biomonitoring perfluorinated compounds in Catalonia, Spain: concentrations and trends in human liver and milk samples. Environ Sci Pollut Res Int. 2010;17:750-758. 
25. Panaretakis T, Shabalina IG, Grander D, Shoshan MC, DePierre JW. Reactive oxygen species and mitochondria mediate the induction of apoptosis in human hepatoma HepG2 cells by the rodent peroxisome proliferator and hepatocarcinogen, perfluorooctanoic acid. Toxicol Appl Pharmacol. 2001;173:56-64.

26. Yao X, Zhong L. Genotoxic risk and oxidative DNA damage in HepG2 cells exposed to perfluorooctanoic acid. Mutat Res. 2005; 587:38-44.

27. Nieto FJ, Iribarren C, Gross MD, Comstock GW, Cutler RG. Uric acid and serum antioxidant capacity: a reaction to atherosclerosis? Atherosclerosis. 2000;148:131-139.
28. Eraly SA, Vallon V, Rieg T et al. Multiple organic anion transporters contribute to net renal excretion of uric acid. Physiol Genomics. 2008; 33:180-192.

29. Nakagawa H, Hirata T, Terada T, et al. Roles of organic anion transporters in the renal excretion of perfluorooctanoic acid. Basic Clin Pharmacol Toxicol. 2008;103:1-8.

\section{Publish your work in this journal}

Clinical Epidemiology is an international, peer-reviewed, open access journal focusing on disease and drug epidemiology, identification of risk factors and screening procedures to develop optimal preventative initiatives and programs. Specific topics include: diagnosis, prognosis, treatment, screening, prevention, risk factor modification, systematic

Submit your manuscript here: http://www.dovepress.com/clinical-epidemiology-journal

\section{Dovepress}

reviews, risk \& safety of medical interventions, epidemiology \& biostatical methods, evaluation of guidelines, translational medicine, health policies \& economic evaluations. The manuscript management system is completely online and includes a very quick and fair peer-review system, which is all easy to use. 